\title{
The Concept of Hometown in German, Russian and Vietnamese Cultures (Experimental Studies)
}

\author{
Dina F. Mymrina \\ Associate professor, National Research Tomsk Polytechnic University, Tomsk, Russia \\ Email:dina_mymrina@yahoo.com \\ Maria O. Abdrashitova \\ Associate professor, National Research Tomsk Polytechnic University, Tomsk, Russia \\ Email: abdrashitova@tpu.ru
}

\section{Doi:10.5901/mjss.2015.v6n3s1p499}

\section{Abstract}

The study of the concept hometown, reflecting national pictures of the world of different ethnic groups, appears to be an important research problem in modern culture study. It is a well-known fact that concepts differ between nations, cultures and periods of time in their content which is socio-culturally determined. The topic of the research is considered relevant due to culture bearers' awareness of the phenomenon of hometown as well as the fact that the process of urbanization can be treated as one of the main global tendencies in the present-day society. The experimental study, dealing with the description and analysis of the content of the concept hometown, which is complex in nature, reveals similarities and differences in the perception of hometown in German, Russian, and Vietnamese cultures. In particular, most common and most frequent associative features of the image under study, discovered for the three cultures, include close people, specific landscape, cultural environment, local cuisine. The distinctive features of the image tend to demonstrate differences in the perception of hometown, which can have social, economic and demographical explanation.

Keywords: association experiment, concept, structure of the concept, hometown, cultural linguistics.

\section{Introduction}

Since the process of urbanization can be regarded as one of the main tendencies characterizing modern culture, the problem of city and its representation in public consciousness is of crucial importance in recent humanitarian interdisciplinary studies. Thus, the cultural space called the city (or town) has raised many questions concerning city's identity and image (Evans and Show, 2004; Garcia, 2004, 2005; Avraham 2004; Duncan and Ley, 2013; Dinnie, 2010), emotional attitude towards urban space (Slater and Anderson, 2012; Pile, 2010). A solid amount of the works is devoted to the investigation of particular cities either big or small (Calcutta, Bat Yam, New York, Glasgow) considering the immediate problems of the cities reflected in their images and citizens' world view (Acharya, 2013; Boland, 2008, McCarthy, 2002).

This study is focused upon specific perception of a native city or a hometown reflected in three national cultures. For convenience of the research we treat the phenomenon of hometown as a concept constituting the world view of collective consciousness represented in culture.

The possibility of employing the term concept is due to quite recent works of Laurence and Margolis, 1999; Rey, 1999; Smith, 2004; Lakoff, Johnson, 1980 as well as the development of cognitive linguistics, philosophy of mind, cognitive psychology, where concept is considered as a picture or idea of an object or phenomenon of the reality comprising notional level combined with cultural social and personal relevant background.

Despite the fact that there exists plurality of concept definitions provided by Clark, Marshall, 1981; Croft, Alan, 2004; Dillon, 2000; Evans, 2009; Guzii, 2014; Talmy, 2000, the authors of this paper define concept as "a discrete cognitive phenomenon, the main unite of person's mental code characterized by a relatively regularized structure. It presents the result of personal and community's cognition embodying complex, encyclopedic information on the reflected object or phenomenon and the interpretation of the information as well as the attitude to this phenomenon presented in national social consciousness" (Popova, Sternin, 2006). Thus, the concept is a cultural unit allowing us to reveal the specifics of image structure and content. 
Obviously, concepts belonging to one and the same culture tend to demonstrate common features in their inner structure, whereas concepts denoting one and the same phenomenon in different cultures can vary in their structure and inner meaningful properties. Variation of concepts' meaning implying the same object or phenomenon but functioning in different cultures is frequently caused by extra linguistic factors including cultural, socio-economic and demographic environment.

The concept hometown presents some common and specific features. It reveals its universal properties which are due to people's awareness of the denoted phenomenon. It is assumed that cultural public consciousness is familiar with phenomenon of place of birth or living. Hometown is defined as "the city or town where one was born or grew up; the place of one's principal residence" (Merriam Webster Online Dictionary). However, we suppose that the representation of the concept studied can vary in different cultures as social, national traditional, political surroundings can affect its content, structure and emotional attitudes, which constitute culture-bound characteristics. The concept hometown can be treated as a robust system of emotional, rational and value judgment about a place of birth or / and residence, composed of the information obtained from difference sources of individual sensation as well as real-life experience.

Consequently, the research is aimed at revealing the representation of a hometown image perceived as a universal cultural phenomenon. The study of hometown image reflected in the three cultures, namely Russian, German and Vietnamese, can contribute to a better understanding of world view peculiarities and their interpretation represented in public national consciousness as well as to promote indication of similar and distinctive features of European and Asian cultures.

\section{Materials and Methods}

\subsection{Method}

Concepts constitute the basic units of the world view reflecting values of both an individual person and the entire linguistic community. They are part of the system and are constantly affected by other concepts. Each concept has a structure which is subject to changes as it provides an understanding of continuously changing reality. Besides, the content of a concept normally remains within the frame of distinct culture and particular time period.

It is often assumed that concepts are units with a complex structure, where various fields, zones, components can be distinguished. First of all, the figurative content of a concept should be mentioned which can be realized in two components: figurative-perceptual component, dealing with the reflection of a fragment of reality through the organs of senses, and figurative-cognitive component, which forms a metaphorical interpretation / conceptualization of reality (objects or phenomena). Next, the informative content of a concept (close to the encyclopaedic dictionary definition of the word itself) comprises cognitive features which determine the most important features of an object or a phenomenon. Then, the interpretive field includes cognitive features which assess and interpret the basic informative content of the concept. All in all, the structure of a concept can be described only when all the cognitive features of the concept are revealed and its content is defined and described.

There are different approaches to the analysis of concepts as well as there exist various ways of their description and interpretation, which is due to the use of different research materials. For instance, in order to identify the specific structure and the content of cultural concepts, the analysis of textual data or dictionary entries can be conducted. These are traditionally considered to reflect many aspects of the concept content but, on the other hand, they do not often provide emotional and evaluative understanding of a concept, which can be treated as a significant drawback of the method selected. In the present study of cultural dominants, we focus on the material obtained in an experimental test, namely association experiment, which is widely used in psychology, sociology, psychiatry, psycholinguistics etc.

Association experiment has proved to be a powerful technique used by researchers in linguistic studies (Deese, 1965; Cramer, 1968; Nelson, McEvoy, Schreiber, 2004; Kubryakova, 1996; Leontiev, 1997; Karaulov, 2000; Ufimtseva, 2001; and others). It is often claimed that association experiment is of greater importance compared to other methods and techniques used to reconstruct linguistic consciousness as it provides researchers with the insights about mental lexicon, shows how it is organized and allows exploring the verbal memory of the people. "An organized interrelation of verbal associations represents the storage of knowledge in human memory, and, therefore, association tests are a valuable source of unique linguistic and paralinguistic information as they emphasize most relevant features of the word stimulus semantics in native speakers' viewpoint" (Leontiev, 1997).

The experimental method employed in the present study (free association test or word association test) is aimed at revealing those details of the perception of the fragment of reality which are most relevant at the moment of speech. Besides, it can provide adequate description of culturally-bound images that characterize linguistic consciousness of a 
group of people. In a free association test, respondents are normally asked to give word / words that come to mind after they think about a word stimulus given to them (the respondents are not limited in the type or number of verbal responses they may provide). The associations may reveal valuable information on the content and the structure of the concept. Analyzing the frequency of reactions given, a researcher can draw a conclusion on their relevance / irrelevance to the respondents. At last, the data obtained in a free association test are an important source of information for cross-cultural studies which may also reveal the forms of axiological perception of the world, factors that determine human behaviour and spiritual / material culture of the people.

Thus, applying association experiment, researchers may identify the components of the national world view of this or that ethnic group, which would reflect its most relevant features and the character of national culture. As N. V. Ufimtseva believes, association method can be considered as "'an association profile' of the images of consciousness specific for a given culture and language which integrates mental and sensory knowledge that a particular ethnic group possesses" (Ufimtseva, 2001).

\subsection{Participants}

The participants were 60 National Research Tomsk Polytechnic University (TPU) students: 20 Russian and 20 Vietnamese third-year - fifth-year students of the Institute of International Education and Language Communication (TPU) and 20 German students, participating in the academic exchange programmes. They were between 19 and 25 years old. The choice of the cultures will allows us to determine the degree and the character of social and cultural dependence of the concept hometown that can be found among Russian, European and Asian speakers of the given age group.

\subsection{Materials}

One word, the noun hometown was selected as a word-stimulus for the purpose of the study.

The hypothesis for the experiment is the idea that the main content of the components of the concept hometown, on the one hand, should demonstrate similarities within the cultures studied, on the other hand, should reveal differences that are socially and culturally predetermined.

\subsection{Procedure}

In the free association test, the respondents were presented with the word-stimulus hometown in the written form and were instructed to supply one or more words that first came to their mind. The word-stimulus was written in the middle of the page and was followed by a blank space in which participants had to write the first words that they could think of. The participants had 5 minutes to supply their responses. The experiment was conducted in the students' classrooms at TPU. The respondents were asked neither to talk nor to somehow react during the test.

\section{Results and Discussions}

Analyzing associations to hometown, we take into account the following factors: 1) objective characteristics of the state and degree of development of the hometown, as they may have a rather serious effect on the way a person sees and treats their home place; 2) the fact that the present study focuses on fragments of the world view, the mental world and the national character of native speakers of the Russian, Vietnamese and German languages, which are found to be reflected in verbal associations.

As can be observed from Table 1, which summarizes the results of the free association test and presents the main components of the structure of the concept hometown in German, Russian and Vietnamese cultures, the data obtained find minimal differences in the number of the components identified. 
Table 1. The structure of the concept hometown in German, Russian and Vietnamese cultures

\begin{tabular}{|c|c|c|}
\hline German & Russian & Vietnamese \\
\hline \multicolumn{3}{|c|}{ The figurative-perceptual component } \\
\hline+ & + & + \\
\hline \multicolumn{3}{|c|}{ The figurative-cognitive component } \\
\hline+ & + & + \\
\hline \multicolumn{3}{|c|}{ The informative content } \\
\hline+ & + & + \\
\hline \multicolumn{3}{|c|}{$\begin{array}{l}\text { The interpretive field } \\
\text { The encyclopaedic zone }\end{array}$} \\
\hline+ & + & + \\
\hline \multicolumn{3}{|c|}{ The regulative zone } \\
\hline- & + & - \\
\hline \multicolumn{3}{|c|}{ The utilitarian zone } \\
\hline+ & + & + \\
\hline \multicolumn{3}{|c|}{ The evaluative zone } \\
\hline+ & + & + \\
\hline \multicolumn{3}{|c|}{ The social-cultural zone } \\
\hline+ & + & + \\
\hline
\end{tabular}

Table 1 shows anticipated similarities in the three cultures under study; however, a more detailed analysis of each of the elements identified demonstrates rather significant differences, associated with a number of factors.

Let us consider the reactions that explicate levels in the structure of the concept hometown. Note that in the present study the word-reaction is accompanied by figures (indicating the number of reactions provided by the respondents) given in round brackets $(2,3,4$ etc.), which allows revealing the relevance of the respective images in the structure of the concept and identifying its content.

So, the analysis of the results of the psycholinguistic experiment (verbal reactions - associations to the wordstimulus hometown) reveals the following structure of the concept:

\subsection{The figurative component}

The figurative component in the structure of the concept is determined by "neurolinguistic nature of a universal objective code: sensory image encodes the concept, forming a unit of a universal objective code" (Popova, Sternin, 2007). As it was mentioned above, in the structure of the concept, it can be represented by a figurative-perceptual component (reflecting a fragment of reality by means of sense organs) and a figurative-cognitive component (denoting a metaphorical perception of a phenomenon).

\subsubsection{The figurative-perceptual component}

The figurative-perceptual component of the concept correlates with the sensory perception images of hometown. For instance, home place, reflected in the German consciousness, is primarily actualised through physical sensations (auditory and taste characteristics of objects) and is realized through verbal reactions: good, tasty food (5), music (4).

In Russian culture, this component is conveyed mainly through visual images: comfortable (6), green (5), clean (3), gray (2) and tactile images: cold (5).

The figurative-perceptual component of the Vietnamese concept hometown is revealed through visual images: clean (8) and various taste characteristics: delicious food (6), delicious rich cuisine (5), duck (2), rice (2).

\subsubsection{The figurative-cognitive component}

The figurative-cognitive component of the concept hometown in German culture is realized through verbal reactions, associated with close people and relatives: parents (6), friends (5), family (4) as well as landscape: nature (4).

The figurative-cognitive component of the Russian concept is also conveyed through verbal responses, related to family, friends, and pets: parents (3), friends (3), cat (2); home: home (5); significant objects in the surrounding environment: school (3), and nature: nature (5), forest (4). Besides, Russian participants attribute human qualities 
(physical ones) to the concept hometown: young (3).

A similar situation is found in the Vietnamese, where the concept reveals human qualities (emotional ones): calm (5), friendly (4), hospitable (3). It should be noted that all the reactions received are positive. Besides, as in two previous cases, the figurative-cognitive component of the concept is realized by means of verbal responses, associated with relatives: family (2).

\subsection{The informative content}

The informative content of the concept is very close to the definition of the basic word (hometown is the town where a person was born or grew up), representing the concept and indicating features that differentiate the denotation of the concept.

The informative content represents the notional component of the concept, which can give individually-specific and stereotypical culturally-determined perception of an object or a phenomenon in different cultures.

So, the informative content of the concept hometown in German culture is represented by a verbal reaction: homeland (6). It appears that the concept hometown has features, characterizing the space both as a place of birth and as a native country or motherland.

The informative content of the concept hometown in Russian culture is determined by cognitive features that denote the concept itself as a place of birth or place as a particular geographical location: homeland (2), Siberia / Siberian (2).

Similar informative content of the concept under study, represented in the Vietnamese culture, is actualised through reactions: near the capital (2), capital Hanoi (2).

\subsection{The interpretive field}

The interpretive field includes cognitive features which evaluate and interpret the concept. Taking into account that there is a large possibility of various interpretation of the concept content, the following zones are distinguished in the interpretive field: encyclopaedic, regulatory, utilitarian, evaluative, social-cultural and paremiological ones.

It should be noted here that due to the experimental character of the work, the paremiological zone is not considered in the present study.

\subsubsection{The encyclopaedic zone}

The encyclopaedic zone of the interpretive field "combines cognitive features of the concept which are the result of the experience gained, training, and interaction with the denotation of the concept" (Paleeva, 2010). For instance, the encyclopaedic zone of the concept hometown, discovered in German culture, contains associations, indicating specific geographical landscape: field (3), mountains (3).

The encyclopaedic zone of the concept hometown in Russian culture also includes characteristics of the landscape: lakes (2), river / Tom (2); characteristics that are learnt by interacting with the denotation of the concept, for example, size characteristics: small (9). It should be mentioned that reactions of the encyclopaedic zone that demonstrate a purely individual character are not considered in the present study.

The data of the association experiment show that the encyclopaedic cognitive features of the concept hometown in Vietnamese culture include size and numerical characteristics: small (7), large (3), crowded (4), and chronological characteristics: ancient (3), modern (2). The encyclopaedic zone of the concept hometown also includes factors which specify nature and landscape: river (6), sea (6), beach (6), mountains (5), island (3); characteristics of infrastructure: port (4), bridge (3), and building (2).

\subsubsection{The regulative zone}

It was found out that the regulative zone of the interpretive field is not present in the structure of the concept which is modeled for German culture in the present psycholinguistic experiment. Normally, this zone includes reactions, which provide instructions and refer to control, determine someone's behaviour in relation to the denotation of the concept.

In this study, no such reactions among the German respondents were obtained.

The Russian reactions in the regulative zone of the concept under study are also not numerous. The behaviour algorithm, which is within the scope of the concept, is reflected in the reactions, such as have to leave (3) and leave (2), 
which implies the idea of leaving the hometown.

As it was found out for German culture, no regulative zone was identified in the structure of the Vietnamese concept of hometown.

\subsubsection{The utilitarian zone}

The utilitarian zone of the interpretive field of the concept hometown includes the reactions of respondents which actualize the pragmatic characteristics of the concept denotation. For the German participants, the zone includes reactions, which are related to sports: roller skating (3), football (3) and employment and studies: university (3), education (3), the possibility of self-realization (2). Thus, in German culture, the zone of the concept actualizes potential activities (sports or training activities) as well as activities as an opportunity for self-expression.

In Russian culture, positive pragmatic characteristics of the hometown are realized, for instance, a town where it is nice / good to live (2), there is an opportunity to receive a good education (2). The zone also includes reactions, associated with production, traditional occupations, natural resources, and pastime: miners (4), coal (4), plant (3), oil (2), fishing (2), and hunting (2). The list of reactions also includes associations with student life: university (5), students (3).

For the Vietnamese, the utilitarian zone is represented by industrial production, traditional occupations, and natural resources: industry (2), tourism (2), fishing (3), and oil (2). This zone includes responses related to transport / means of transport: bicycle (3).

\subsubsection{The evaluative zone}

The evaluative zone of the interpretive field of the concept hometown in German includes reactions, representing the attitude and the evaluation (aesthetic, ethical, emotional) of the concept denotation. Thus, for the German respondents, the concept of hometown actualizes the following personal evaluative reactions: youth (4), a happy childhood (4), a sense of security (4), love (4), good atmosphere (4), happiness (3), freedom (3), openness, transparency (3). Thus, a positive emotional evaluation of hometown by the German participants can be observed. Also, numerous reactions, associated with the inner (personal) feeling of happiness, security, and, as a consequence, possibility of open and sincere interaction with the world should be noted.

In contrast to the German respondents, the evaluative zone of the concept hometown in the Russian consciousness can be described as ambivalent, where the word-stimulus may produce contradictory associations and may be evaluated differently (usually through single-individual reactions). In addition, some of the reactions analyzed can be treated as negative, which is indicative of some topical social problems: poverty (3), crime (3), and dead end (2).

The Vietnamese associations, revealed in the evaluative zone of the concept hometown, are positive: beautiful (14), quiet (5), friendly (4), hospitable (3). Also, verbal reactions to hometown include: good people (2), nice people (2), but, at the same time, hard life (2).

\subsubsection{The social-cultural zone}

The social-cultural zone of the interpretive field reveals cognitive features, characterizing the connection between the concept and the cultural and general life of the community. So, in the consciousness of the German respondents, the zone includes verbal responses, dealing with cultural and national traditions: culture (5), holidays (4), October fest (3). Cultural specificity, actualised in the concept, is represented by means of reactions, describing the transport system: carfree streets (3), the pedestrian zone (3).

The Russian cognitive socio-culturally specific reactions, reflecting the connection between the concept hometown and everyday life and culture of people, include architectural features, monuments, sites: wooden architecture (2), a monument to the rouble (2), rich in cultural sites (2), Chekhov (2), orthodox (2), parks (2), fountains (2), traffic jams (3).

The social-cultural zone in Vietnamese culture is represented by the following verbal, mostly, socio-culturally specific reactions: monument (5), a town where there are many historic sites (4), Hanoi Opera House (3), Lake of the Restored Sword (one of the major historical and cultural sites of Hanoi) (2), Thang Long, the ancient capital (Flying dragon) (2), Buddhism (2), Do Son Buffalo Fighting Festival (2), architecture, reminding of French architecture (2), Ho Chi Minh Mausoleum (2). 


\section{Conclusion}

The study reveals the structure of the concept hometown and analyses the perception of the concept in the Russian, German and Vietnamese national consciousness. All the associations obtained in the present study allow reconstructing the world views of the three cultures which reflect the peculiar features of the national character and world perception, specific characteristics of national culture. The results of the experiment also demonstrate a connection between the level of socio-economic development of a region and word-reactions to the stimulus-word.

So, the concept hometown in German culture is represented by the images of motherland, positively associated in the national consciousness with people, often family and relatives, landscape, cultural characteristics, special holidays, food and music, opportunities for self-realization and studies.

The Vietnamese culture includes the concept hometown, reflecting the perception of the concept denotation as a place, positively associated with people living there (to a lesser extent, family), a rich local cuisine and products, rich and diverse cultural environment, specific landscape and infrastructure.

The Russian culture representatives identify hometown as a place of birth, in some cases, associated with Siberia (where the experiment was conducted). Here a special emphasis is given to visual and tactile associations, evaluated mostly positively. Hometown is also associated with home and relatives, animals, nature, landscape features, natural resources, cultural sites, some social problems (not represented in the other two linguocultures), and some algorithms for actions that are associated with hometown (associations, which are not present in German and Vietnamese cultures). It is obvious that all the results obtained are unique material, which allows us to create 'an association profile' of each of the cultures.

In conclusion, observations on the content and the study of the results obtained from various languages contribute to our understanding of specific features of the world perception and its evaluation represented in the national linguistic consciousness and allow identifying both similarities and differences in the European and Asian cultures under study.

\section{Acknowledgements}

This work is funded within the framework of realization of Strategic Programme on National Research Tomsk Polytechnic University Competitiveness Enhancement in the Group of Top Level World Research and Academic Institutions.

\section{References}

Acharya, Chandrika, (2013), Real Cities Concept cities and the Formation of Cultural Identities. [Online] Available: https://www. academia.edu/237265/Real_Cities_Concept_Cities_and_the_Formation_of_Cultural_Identities (15.12.2013).

Avraham, E. (2004). Media strategies for improving an unfavorable city image. Cities, 21(6), $471-479$.

Boland, P. (2008). The construction of images of people and place: Labelling Liverpool amd stereotyping Scousers. Cities, 25(6), 335369.

Clark, H., Marshall, C. (1981). Definite Reference and Mutual Knowledge. In A.K. Jpshi, B.L. Webber, \& I.A. Sag (Eds.), Elements of Discourse Understanding (pp. 10-63). NY: Cambridge University Press.

Cramer, P. (1968). Word Association. NY: Academic Press.

Croft, W., Alan, D. (2004). Cognitive Linguistics. NY: Cambridge University Press.

Deese, J. (1965). The Structure of Associations in Language and Thought. Baltimore: The Johns Hopkins Press.

Dillon, J. (2000). The Question of Being. In: Jacques Brunschwig, Geoffrey E. R.Lloyd (eds.), Greek Thought: A Guide to Classical Knowledge (pp.48-94). Cambridge: Cambridge Mass.

Dinnie, K. (2010). City branding: Theory and cases. New York: Palgrave Macmillan.

Duncan, J. S., \& Ley, D. (2013). Place/culture/representation. New York and London: Routledge.

Evans, V. (2009). How Words Mean. New York: Oxford University Press.

Evans, G., \& Shaw, P. (2004). The contribution of culture to regeneration in the UK: A review of evidence. London: DCMS.

Garcia, B. (2004). Cultural policy and urban regeneration in Western European cities: Lessons from experience, prospects for the future. Local Economy, 19(4), 312-326.

Garcia, B. (2005). Deconstructing the city of culture: The long-term cultural legacies of Glasgow 1990. Urban Studies, 42(5-6), 841-868.

Guzii, T. (2010). Value component of linguocultural concept GOD in the Old English language. European Journal of Science and Theology, 10(6), 99-104.

Karaulov, Y. N. (2000). The markers of national mentality in the associative-verbal net (pp. 191-206). Linguistic consciousness and world picture. Moscow: Linguistic Institute RAN.

Kubrjakova, E. (1996). Concept. In E. S. Kubrjakova (Eds.), A shorter dictionary p cognitive terms (pp. 90-93). Moscow: Izd-vo MGU.

Lakoff, G., Johnson, M. (1980). The metaphorical structure of the human conceptual system. Cognitive science. 4. 195-208.

Laurence, S. \& Margolis, E. (1999). Concepts and Cognitive Science. In E. Margolis \& S. Laurence (eds.), Concepts: Core Readings (pp. 
3-81). Cambridge, MA: MIT Press.

Leontiev, A. (1997). Elementary psycholinguistics. Moscow: Smysl.

McCarthy, J. (2002). Entertainment-led regeneration: The case of Detroit. Cities, 19(2), 105-111.

Merriam - Webster Online Dictionary [Online] Available: http://www.merriamwebster.com/ dictionary/ hometown] (3.02.2015).

Nelson, D. L., McEvoy, C. L., \& Schreiber, T. (2004). The University of South Florida word association, rhyme, and word fragment norms. Behavior, Research methods, Instruments, \& Computers, 36, 402-407.

Paleeva, E. (2010). Concept "Money" in Russian linguistic consciousness. Memoirs. Scientific journal of Kursk State University, 3(15), 87-94.

Pile, S. (2010). Emotions and affect in recent human geography. Transactions of the Institute of British Geographers, 35(1), 5-20.

Popova, Z., Sternin, I. (2007). Cognitive linguistics. Moscow: AST: Vostok-Zapad.

Popova, Z., Sternin, I. (2006). Semantic-cognitive language analysis. Voronezh: Istoki.

Rey, G. (1999). Concepts and Stereotypes. In E. Margolis, \& S. Laurence (Eds.), Concepts: Core Readings (pp. 279-301). Cambridge, Massachusetts: MIT Press.

Slater, T. and Anderson, N. (2012). The reputational ghetto: territorial stigmatisation in St. Paul's, Bristol, Transactions of the Institute of British Geographers, 37 (4), 530-546.

Smith, B. (2004). Beyond Concepts, or: Ontology as Reality Representation, Formal Ontology and Information Systems. Proceedings of the Third International Conference, 1, 73-84.

Talmy, L. (2000). Toward a Cognitive Semantics. Concept Structuring Systems, 1, 104-118.

Ufimtseva, N. (2001). Comparative study of Slavic linguistic consciousness. In I. A. Sternin (Ed.), Methodic problems of cognitive linguistics (pp. 65 - 71). Voronezh: VGU. 